\title{
The 1991-2005 National Solar Radiation Database
}

The success of any solar energy installation depends largely on the site's solar resource. Therefore, detailed knowledge of an area's solar resource is critical to installation planning and siting. To help with these efforts, the National Renewable Energy Laboratory (NREL) and the National Climatic Data Center (NCDC) have updated the National Solar Radiation Database (NSRDB). Since 1992, the database has provided solar planners and designers, building architects and engineers, renewable energy analysts, and countless others with extensive solar radiation information.

The 1991-2005 NSRDB contains hourly solar radiation (including global, direct, and diffuse) and meteorological data for 1,454 stations. This update builds on the 1961-1990 NSRDB, which contains

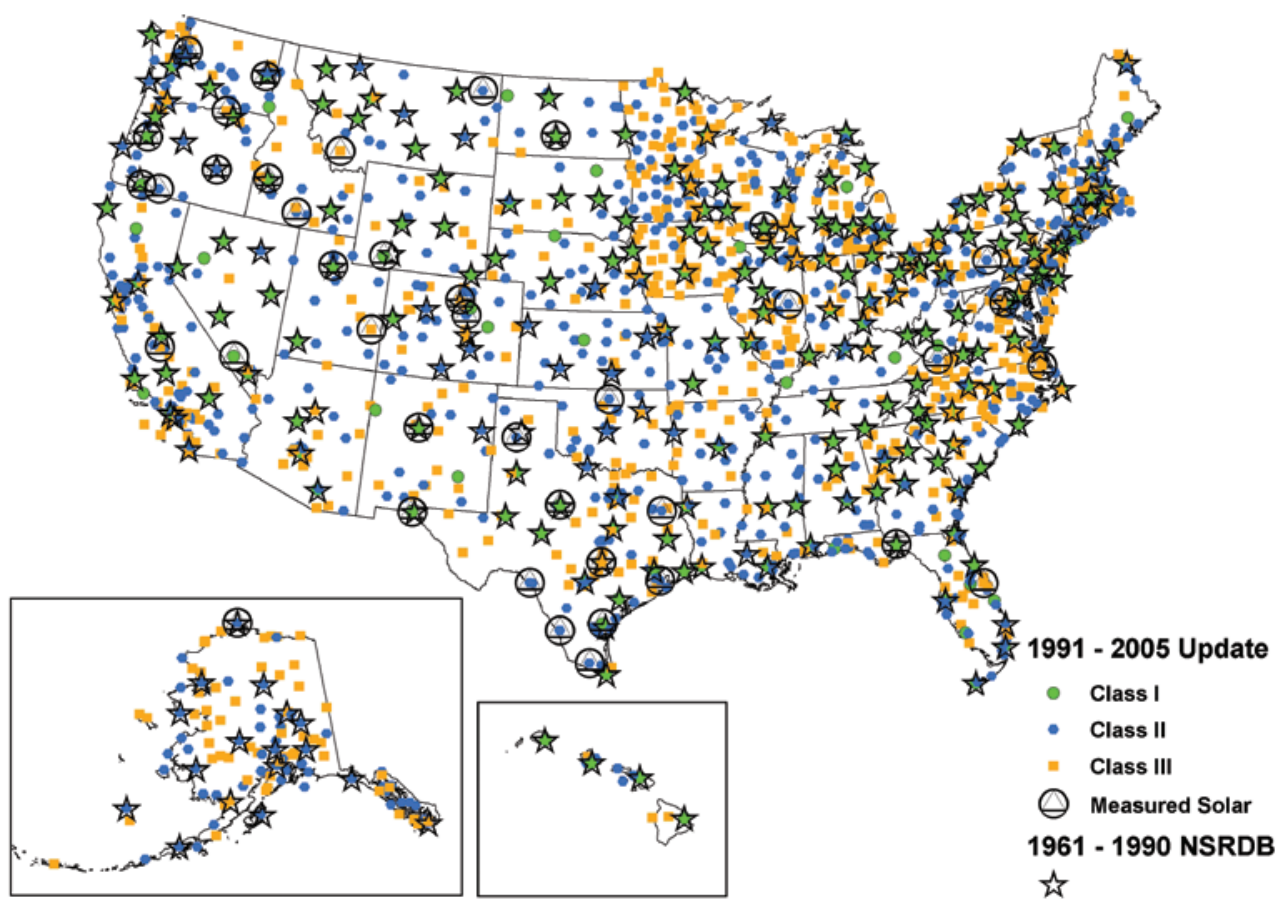

Distribution of 1961-1990 NSRDB sites and 1991-2005 NSRDB sites by class and measured solar data data for 239 stations. The update includes the conventional time series for NSRDB ground stations as well as a one-tenth-degree gridded data set that contains hourly solar records for 8 years (1998-2005) for the United States (except Alaska above $60^{\circ}$ latitude) for about 100,000 pixel locations (at a nominal 10-km-by-10-km pixel size).

\section{Station Classification}

To increase data quantity, developers relaxed the standard of serial completeness mandated by the 1961-1990 NSRDB. In the update, all gaps in station records were filled, and the stations were classified by data quality. The 221 Class I stations have a complete hourly data set for the 1991-2005 period and were produced with the best available input data. The 637 Class II stations have a complete hourly period of record, but they have a higher uncertainty because of lower-quality input data. The 596 Class III stations contain gaps in the period of record but have at least 3 years of data that may be useful for some applications.

\section{Measured Data}

Forty stations in the updated NSRDB include measured solar data, which was supplied by:

- The Atmospheric Radiation Measurement Program, U.S. Department of Energy

- The Florida Solar Energy Center, State of Florida

- The Integrated Surface Irradiance Study and Surface Radiation Budget Measurement Networks, National Oceanic and Atmospheric Administration Air Resources Laboratory and Earth System Research Laboratory Global Monitoring Division

- The Measurement and Instrumentation Data Center, National Renewable Energy Laboratory

- The University of Oregon Solar Radiation Monitoring Laboratory Network

- The University of Texas Solar Energy Laboratory. 


\section{Data Set} Distributor

NCDC

NCDC

NSRDB solar and Integrated Surface Database meteorological fields (no data filling)

NSRDB solar fields (no meteorological)

SUNY 10-km gridded data

NSRDB statistical summaries

NSRDB research solar fields (no meteorological)

${ }^{\mathrm{a}}$ No-cost
${ }^{\mathrm{b}}$ No fee.

A significant difference between the 1961-1990 and 1991-2005 NSRDBs involves data storage. In the original, measured data were merged with modeled data such that a seamless data set of solar radiation values was produced. (The model essentially filled gaps in the measured data.) The update includes fields for both, which allows users the flexibility to choose modeled or, if available, measured data for an application.

\section{Data Access}

The updated NSRDB is distributed via the Internet. NCDC distributes a conventional data set that includes modeled and measured (when available) solar data and key meteorological observations. It also distributes the $10-\mathrm{km}$ gridded data set and a ground-based solar-only data set at no cost and will include the solar data in its Integrated Surface Database infrastructure (without any filled meteorological data). NREL distributes a superset of the solar data without any meteorological fields. This solar research data set includes all modeled data, special clearsky data fields, and other atmospheric components.

\section{User's Manual}

Users interested in the NSRDB should start with the NSRDB user's manual, which is available at http:// www.nrel.gov/docs/fy07osti/41364.pdf. This document describes the data and how the database was developed. The manual includes a complete list of stations and a data quality summary for each site.

\section{Project Participants}

Primary project funding came from the Department of Energy. Additional support was provided by:

- The Atmospheric Sciences Research Center, State University of New York at Albany

- Climate Systems Branch, National Aeronautics and Space Administration

- National Climatic Data Center, U.S. Department of Commerce

- Northeast Regional Climate Center, Cornell University

- Solar Consulting Services, Colebrook, New Hampshire

- Solar Radiation Monitoring Laboratory, University of Oregon.

\section{Additional Information}

For more information, contact Steve Wilcox at Stephen_Wilcox@nrel.gov or 303-384-7785. 